MARS

\section{Lost in the Dust}

from our Soviet Correspondent

THE partial disappointments of the current Soviet Mars investigations caused by the failure in transmission from the landing capsule from Mars 3 and by the ever-increasing dust-storms, which are now apparently seriously interfering not only with direct observations from the orbiting Mars 2 and 3 probes but also with supporting observations from Earth, do not seem to be causing the programme planners undue despondency. Press interviews given by leading figures in the programme, notably by Academician A. A. Blagonravov, head of the Soviet Commission on Space Exploration, give a highly optimistic view of the future of their Mars programme.

In outlining Soviet plans, Blagonravov stresses that for the immediate future, exploration of Mars will be by automata only. The success of Lunokhod, and the achievement, in Mars 2 and Mars 3 of automatic control systems that will function without command from Earth, have given a practical demonstration of the feasibility of this approach, in spite of the unexplained breakdown of transmissions from the Mars 3 landing capsule. Technical problems of fuel and payload, too, hints Blagonravov, will make a manned Mars mission feasible only when intermediate orbital stations (on the Tsiolkovskii plan) have been established. Moreover, microbiologist Vasilii M. Shilov (Pravda, January 1, 1972) says that the presence of microbes in the Martian atmosphere is "quite probable"-a further reason for confining future explorations to automatic devices. At least, he suggests, a sample of Martian soil should be brought back to Earth, after the manner of the Luna 16 experiment, before any manned mission is planned. This approach seems to suggest a change in policy from the mid$60 \mathrm{~s}$, when teams of trainee cosmonauts were confined under simulated spacecraft conditions for times comparable with a Mars expedition.

Yet even with its failures, the current programme is yielding some significant data. Writing in Pravda, Academician G. Petrov asserts that unlike the United States Mariner programme, which is primarily a photographic project, the Soviet probes carry devices to investigate relief, radiation and photometry.

The special equipment of the Mars probes, says Petrov, includes an infrared radiometer, consisting of a pair of miniaturized telescopes, one directed at the planet and one at space, capable of receiving infrared radiation from an object cooled to $-100^{\circ}$ C. The temperature measurements from Mars 3 (at an orbital distance of some 1,500 $\mathrm{km})$ are averaged over a segment of diameter $30 \mathrm{~km}$. The low-temperature range of this device allows accurate monitoring of the "night" as well as the "day" side of the planet. The new spectroscopic device for measuring relief is similar in principle to apparatus used in measurements from Earth, but whereas these could only distinguish features of $1,000 \mathrm{~km}$ and more wide, the new equipment can detect features down to 12 to $15 \mathrm{~km}$.

Another special apparatus measures the brightness of the planet in the visible range, from 4000 to $7000 \AA$. A special study is being made in the brightness difference at the terminator. It is hoped that the data from this experiment will provide information concerning the aerosol (dust) content of the atmosphere and its nature.

\section{OCEANOGRAPHY \\ Deep Diving}

From La Recherche

THE French Centre National pour l'Exploitation des Océans (CNEXO), in the persons of assistant director Jacques Perrot and associate Jacques Riffaud, recently held forth on CNEXO's accomplishments in 1971. Although the results may not be as spectacular as those of the preceding year, it is clear that CNEXO is now getting its second wind and progressing with some interesting projects.

The experimental operations Janus 2 and Physsalis 1 established new world records for deep diving, whereas projects Belouga, Sagittaire and Saturation 3 were useful in both human and animal physiological research. And as well as the Océan programme theme to develop coastal and continental shelf areas under water, CNEXO signed two important exploration contracts with the Compagnie Maritime d'Expertises (COMEX) of Marseilles and Captain Jacques-Yves Cousteau's Centre d'Etudes Marines Avancées (CEMA).

The Belouga operation consisted of four simulated dives to depths of between 100 and 300 metres at $-2^{\circ} \mathrm{C}$, providing the necessary setting to study heat transfer and epidermal heat loss. Data gathered in this operation have already shown that divers engaged in petroleum research and drilling can operate in cold seas. In the Sagittaire tests, held from November 9 to December 3, 1971, under the auspices of COMEX, four men stayed for a long time at a simulated depth of 300 metres inside the COMEX habitat at Marseilles. One of the men ran tests on his osmotic pressure and the effects of the ambient conditions on nervous tension. The purpose of the Saturation 3 scheme, run at CEMA's High Pressure Physiology Laboratory between December 6 and
December 20, 1971, was to study the effects of pressure on the dissolution of gases in the blood stream on two subjects who had been exposed to a simulated depth of 500 metres for 24 hours.

Whereas all the results of these experiments will not be available for some months yet, there remains a need to repeat the tests. It will thus not be realistic to "dive" as deeply as 600 metres during 1972; indeed, such a depth may well not be attainable until 1975 or later. Research operations of this type are clearly designed to meet the needs of both the petroleum industry and the military establishment.

In a more strictly scientific framework, CNEXO has announced plans for a large-scale Franco-American operation when the French will join forces in 1973 with the Woods Hole oceanographic research centre in Massachusetts to develop FAMOUS, the FrunchAmerican Mid Oceanic Underwater Survey. This programme is for forty or so dives during the summer of 1973 just south of the Azores, using Alvin, the bathyscape and the diving saucer as the immersion vehicles. Geophysicists consider this research as highly important, because it will permit on-site study of the vertical movement mechanisms of the material composing the Earth's mantle and compilation of a precise stratigraphy of rift faces by means of core sampling. There is also a magnetism research plan and a relief study of an $8 \mathrm{~km}$ strip of the sea bed, to be recorded by television.

The 1973 research voyage will be preceded in 1972 by a programme of hydrographic charting and exploration Financing of FAMOUS will come, on the American side, from the National Science Foundation, the National Oceanic and Atmospheric Association, and the United States Navy; on the French side, from CNEXO and the French Navy.

\section{Royal Society}

Professor Sir Alan HodgKin, President of the Royal Society, has appointed eight vice-presidents for the coming year. These are Sir Frederick Bawden, director of Rothamsted Experimental Station; Sir Bernard Katz, University College, London; Sir Harrie Massey, University College, London; Professor K. C. Dunham, University of Durham and Institute of Geological Sciences; Professor E. J. W. Barrington, University of Nottingham; Dr H. M. Finniston, British Steel Corporation; Professor R. A. Gregory, University of Liverpool; and Professor R. V. Jones, University of Aberdeen. 